\title{
Upgrade the Socio-Economic System
}

\author{
Ekaterina Yu. Kamchatova ${ }^{1}$, Andrey P. Garnov ${ }^{2}$, Inga O. Protsenko ${ }^{3}$, Gennady V. \\ Zubakov $^{4}$
}

\author{
${ }^{1}$ Department of innovation management, State University of management, Moscow, Russian Federation \\ ${ }^{2}$ Department of Industrial Economics, Plekhanov Russian University of Economics, Moscow, Russian Federation \\ ${ }^{3}$ The Russian Presidential Academy of National Economy and Public Administration, Moscow, Russian Federation \\ ${ }^{4}$ Higher School of Economics, Moscow, Russian Federation \\ *Corresponding author. Email: ey_kamchatova@guu.ru
}

\begin{abstract}
The work is devoted to the study of the dynamics of functioning of socio-economic systems (organizations, local communities and States) from the positions of open systems theory and behavioral Sciences. In the framework of a relatively independent research for the economic system proposed methodology for the analysis of the implementation of its socio-economic nature as a non-linear process in which to investigate the mechanism of the transition objective to the subjective, as well as the reverse influence of subjective activities of economic entities on the essential foundations of the economic system to its multilevel social genomes. The processes of loss of their ability to function effectively in an increasingly complex environment are revealed. The prerequisites for accumulating evolutionary changes and implementing a rapid revolutionary transition through Creative destruction to a new basic model of survival are described. It describes the termination of organizations, the collapse of socio-economic systems that did not make timely changes to the basis of the survival model, as well as the processes of self-preservation for some time of systems with an unchanged organizational basis, despite the actions associated with the change of power. There are marked trends in blurring the boundaries between cognitive and value orientations, indicating interdisciplinary intentions and problem-oriented forms of research activity. The leading directions of scientific progress that change traditional ideas about innovative management, expressed in the search for new ways to form and activate the internal forces of interaction of the economic system, objective laws of management, are highlighted. A fundamental approach to the management and deepening of ideas about the transformational processes that arise under the influence of creative work in the modern economy; about the impact of institutional structures on the implementation of new technical and economic and socio-economic relations. On this basis, we can understand the subordination of relations between the plan and the market, in the process of saving human relations, in the phenomenon of the concept of "human capital", in the implementation of digitalization, in the norms and forms that correspond to the prevailing economic interests.
\end{abstract}

Keywords: General theory of systems, paradigm of thinking, development, institutional environment, evolution, revolution

\section{INTRODUCTION}

The research on the functioning of the economic system is based on a methodology for analyzing the implementation of its socio-economic nature as a nonlinear process, in which the object is the mechanism of transition of the objective to the subjective, and the reverse effect of the subjective type of activity of economic entities on the essential foundations of the economic system, as well as on its social genomes, which are at different levels of development. The paper substantiates the hypothesis that the approach is fundamental for systematization and deepening of ideas about transformational processes that arise under the influence of creative labor in the modern economy; about the impact of the institutional structure on the implementation of new technical and economic and socio-economic relations. On this basis, it is possible to determine the role of subordination between the plan and the market in the process of economizing human relations, in the phenomenon of the concept of "human capital", in the implementation of digitalization, cryptocurrencies in 
norms and forms that correspond to the prevailing economic interests [1].

Addressing this topic is determined by a number of circumstances. First, the contradiction between the declared goal of a breakthrough in the technological and industrial development of the country and the economic and theoretical foundations of the proposed technological solutions, which are limited to market ideas and are narrowly conjunctural in nature.

Measures of regular economic policy, which currently include budgetary, tax, monetary and other forms, do not correspond to the tasks set within the framework of the country's economic development. The solution to this contradiction lies in the need for an integrated approach to the study of the systemic problems of the modern economy and the economic policy pursued by the Russian government. The systematic nature of the problems was highlighted in the speeches of scientists at the St. Petersburg international economic Congress (SIEC2019).

Second, there is the development of an approach to the economization of human relations, which essentially involves the economization of non-economic relations. These processes require a theoretical understanding of the socio-economic nature of economization and the prospects for its reproduction, understanding the need to replace this type of economization by stimulating appropriate activities.

Finally, and third - there is an underestimation of the problem of institutionalization of economic interests in the transformation of the economic system based on a technological breakthrough. Without studying the socialization of motives of behavior of economic entities as the formation of their social form of existence (certain economic interests), it is impossible to study the structure of existing interests, its dynamics, and offer an adequate mechanism for their institutionalization to form the motivational orientation of economic entities to the progressive transformation of the Russian economic system [2].

\section{METHODOLOGY}

The problem of social development of human systems in his writings raised the American psychologist Claire W. graves (1959). His students and followers don Beck and Chris Cowan also found in their research confirmation of Graves 'correct definition of the desire to integrate" bio -", "psycho - " and" socio - " in order to unite human knowledge and destroy academic barriers that clearly distinguish separate scientific disciplines and research areas $[3,4]$. The spiral dynamics proposed by K. Graves as a model " ... provides a common language for covering both local and global problems. It offers a system of views that makes possible holistic thinking and actions in accordance with them" [3] K. Graves stated: "A person, company or society as a whole can only respond positively to those management principles, motivational appeals, educational methods, legal and ethical rules that are acceptable for the current level of human existence" [3]. However, in the work of these psychologists, we see only ascending spirals [4].

In his writings the Russian researcher V. M. Efimov specifies: "The choices that individuals make today are embedded in the actions of yesterday's volitional agents. At the same time ... individuals have, in addition to the rules that are imposed on them by "volitional agents", their own, having deep historical roots, informal rules and beliefs-beliefs, and if they contradict the rules introduced, their implementation is in doubt" (Efimov, 2016). It shows the importance of timely legislative registration of new behavior and educational efforts by those interested in the introduction of these rules (Efimov, 2016). It shows that the institutional environment of modern society changes step-by-step, with each new law, rather than by leaps and bounds, as we interpret revolutionary changes. Graphically, this can be interpreted as a movement along a triangle: from functioning to the emergence and testing of ideas by the leading part of society; consolidation in the form of normative legal acts; getting used to a new level of behavior by other actors, etc. (see Fig. 1).

Psychologist M. Csikszentmihalyi in the work "the Evolution of personality" described the processes of formation of human behavior by analogy with the processes of formation of his physical condition. He used the concept of "meme", introduced in 1976 by Richard Dawkins from the Greek. $\mu \mu \mu \eta \mu \alpha$ (pronounced (mí:me:ma) mīmēma) - imitation of a thing [5]. It is believed that memes are cultural analogs of genes because they are multiplied, modified by natural selection [6]. At the same time," like genes, memes do not act alone, but form a mosaic, forming a comprehensive view of human life and the world around them" [3].

Thus, by the beginning of the XXI century, a new socialevolutionary theory was formed, called the theory of spiral dynamics, shown in Fig. 1.

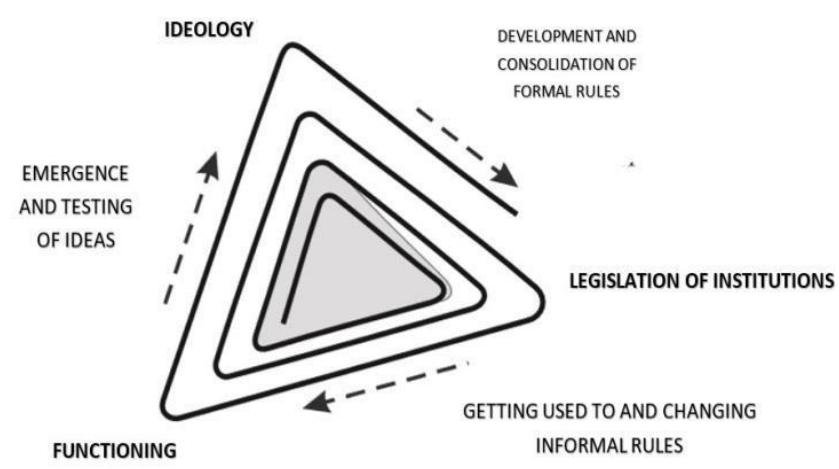

Figure 1 Triangle of cycles of institutional changes

The grey triangle reflects the long Russian "walking in one circle". 
According to the theory of systems [7-9], each component of the system must subordinate its activities to common interests, that is, be guided by a common beginning to ensure mutually agreed activities relative to a single goal of the system. This is a progressive systematization, characterized by the degree of connectivity of elements $\alpha$. As a rule, this systematization is implemented based on centralized management of the organization's activities throughout the hierarchy from top to bottom. Accordingly, alpha leaders are considered the leaders of this activity. Although currently there are Turquoise organizations without middle managers, which $F$. Lala justified by an extremely high level of consciousness of people [10].

On the other hand, most components of the system must maintain their ability to respond to changing external conditions, as a necessary variety [11]. This was originally formulated By W. Ashby for Cybernetics: the diversity of a complex system requires management, which itself must have the necessary diversity $[12,13]$. In General, we are talking about the ability of the system components to adapt themselves to the changing external environment, to adjust the entire system to the new external conditions of their activities. This is the regularity of changes in internal relationships to ensure progressive factorization (decentralization of decisions on the overall activity of the system) and is characterized by the degree of independence of elements in the implementation of system - wide activities- $\beta$. Accordingly, the leaders of such activities can be considered beta leaders, factorization leaders-innovators, which, As E. Rogers justified, are about $2.5 \%$ of all participants. They are the ones who are able to go beyond the existing knowledge and are the first to implement a new behavior [14].

\section{DISCUSSION}

The development of the socio-economic system in the external environment is proposed to be interpreted as a virtual movement along spirally expanding rings (see Fig. 2).

\section{EXTERNAL ENVIRONMENT}

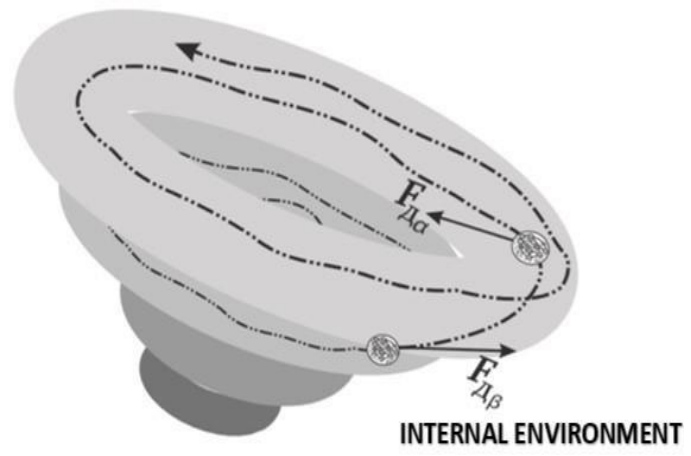

Figure 2 Spiral dynamics of the socio-economic system in the external environment, subsystems in the system

The fundamental results of this research are presented in the author's work "Dynamics of development of socioeconomic systems" [15]. Therefore, we focus only on the conditions of transition to the next, qualitatively more significant stage of stable movement, or the death of the system - the termination of activity as a whole, as well as the option of rolling back to the previous level of stable functioning with some innovations in the activity. It should be noted that the zone of relatively stable movement in a circle is very limited (see Fig. 3).

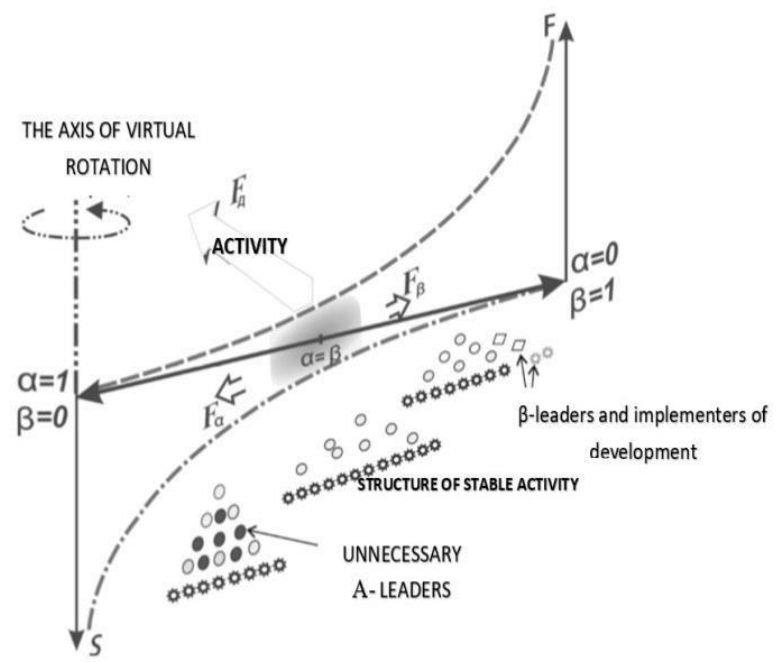

Figure 3 Socio-economic system in the process of virtual movement with fluctuations under the alternating influence of progressive systematization

This constant confrontation of systematization and factorization is vital for any dynamic system and corresponds to the philosophical law of G. Hegel-the unity and struggle of opposites [16, 17]. 
Movement in a circle is relatively stable if the external resource is sufficient for survival in the current model of the socio-economic system, and the maximum possible share of the system components is engaged in productive labor (Fig. 3).

If the organizational model has exhausted the possibilities of survival, but continues to strengthen the systematization (the centripetal forces FDA, $\alpha>>\beta$ prevail), this leads to an accelerated movement along a twisting funnel-shaped spiral. The efficiency of converting an available resource is reduced and there is a lack of competition in the environment. Examples are companies such as Kodak, Xerox, and others that have lost their leading positions, retained only their brands, and changed their operating technologies to low-performing technologies.

Revealing the action of the regularity of hierarchy, or hierarchical ordering, shows a synergistic effect, but until the systematization (S) has become all-dominating. Centralization inevitably leads to increased subordination and suppression of the independence of the components of this hierarchy. The higher the hierarchy levels, the stronger this effect is, up to a destructive distortion of information and even connections in the system [18].

In a multi-stage bureaucratic system, each higher-level and nodal management object needs to have all the information about its subordinates, and it tries its best to get this advantage. Provides higher-level and other node components of the system on which it depends, information in the form and volume that allows you to maintain or increase its significance.

Special information keepers and processors are generated. The volume of redundant information is growing. The number of elements responsible for communication in the system, for the exchange of information, and not for productive activities is multiplied (see figure 3 ).

Figure 3 is a view of the socio-economic system during a virtual movement with the fluctuations under alternating influence of progressive systematization, where $\alpha$ is the virtual force $F \alpha$ and progressive factorization $\beta-F \beta$ virtual force, providing in their opposition stable operation and adaptation to the external environment.

In General, the efficiency of transforming the system of a familiar or, even more so, a decreasing resource from the environment decreases. In Joseph Turner's work "the Collapse of complex communities", it is noted that societies "... create problems that they cannot solve" [19]. In fact, this thesis serves as proof of the idea put forward by Toynbee, which is the possibility of finding a cool to scientific judgment, where complex societies collapse due to the fact that the accepted and implemented model does not correspond to the modern realities of the functioning of economic entities and their adaptation undoubtedly leads to a decrease in the effect of presence in the system and does not create new premises and foundations for its development. The innovation environment, and the low intensity of the innovation field in this case is rather a deterrent to development [20].

\section{RESULTS}

Based on the above, we believe that development is possible only under one of the scenarios presented below. The first scenario is implemented based on basic changes in the organizational model, usually by creative destruction (according to J. Schumpeter) only that prevents the implementation of new interaction procedures in the organizational system. In place of the destroyed ones, new connections are established, a new combination of all the connections in the system is implemented, which was emphasized by J. Schumpeter [21]. Next, you need to master new relationships (Fig. 1). The ideologists of these new relationships are usually beta leaders who identify and test innovations and new behavior. An innovative change in the basis of the organizational model of the socio-economic system is implemented quickly, but step by step [22].

There is a well-known example of the Glorious revolution in England. After the bubonic plague and the severe upheavals that led to the civil war of 1642-1651, it made up for lost time in the world for three decades, practically not changing the model of the device, but changing the kings. First it won back its place in Europe, and then it conquered South America. Compared with other colonial countries, England was looking for ways to use various, not always easily available resources. Therefore, its socioeconomic system in its oscillatory movements significantly deviated in the direction of factorization $(\operatorname{Fd} \beta, \beta>\alpha)$, that is, decentralization. The extension of the principles of English law to all citizens was unprecedented, and from 1689 the court of England began to administer justice "regardless of persons" - in 1698 the monopoly of the Royal African company was abolished. Power has almost passed to the Parliament and an independent court. The formation of an inclusive model of government in England based on pluralistic relations has begun.

Revolution - a radical, radical, deep, qualitative change, a leap in the development of society, nature, or knowledge, associated with an open break with the previous state [23]. Therefore, the Glorious revolution in England can be interpreted as a revolution with rapid step-by-step basic changes in the organizational model of the country, the transition to a higher stage of development of society. Although by step-by-step changes we mean evolutionary transformations.

The second scenario is quite common. It clearly shows the inadequacy of the circumstances of the behavior of those responsible for decision-making and implementation, who have a predominant ability to subordinate and obey (alpha-leaders) and suppressed initiative. If the organizational model does not change in essence, then the instincts of self-preservation naturally begin to prevail in 
the weakening efforts of actors: its leaders increase their attention to protecting their interests, counteract both other $\alpha$-leaders who feel the possibility of intercepting power, and $\beta$-leaders who advocate changing the organizational model. The movement along the twisting funnel to the "black hole" is accelerated. The system will pass the state in which it was still possible to find the strength to reorient to the opposite direction of movement. It is not easy to predict the moment and variant of the change of power, which really represents a coup d'état. The change in power in 2014 in Ukraine can most likely be attributed to the implementation of such a scenario. If indeed the revolution aimed at changing organizational models, are unlikely to be any significant background to the war in the Donbass on the basis of federalism could solve many of the problems of interaction between the Central authorities and the regions, taking into account the interests of regions and not to use the army.

After restoring the organizational model with some improvements, the system will move to a stable activity, but only at a reduced level. Therefore, the next instability develops faster and the next attempt to switch to a different model is made. World experience shows that this may happen several times before the system begins to permanently transition to a new basic model of functioning. This option is possible not only due to the increased activity and cohesion of the factorization forces (beta-leaders), but also due to the significantly worsened socio-economic situation in the country.

Researchers were able to explain the phenomenon of the second scenario from several different positions [13].

In the course of the Glorious revolution, the people of England and their advanced strata, having become selfsufficient, distanced themselves from the government, took steps to separate themselves clearly from the system of the serf state, so they began to demand that the authorities take into account their economic and political interests. The government was forced and, at the same time, very reasonably began to perceive the people as their external environment, and not in the former capacity of faceless subjects. It has not become as resistant to the demands of its new environment as it is in most backward countries. Therefore, the monarchy is still revered in Great Britain, not unlike the fate of the Russian monarch family. Everything in this world is mutual!

\section{CONCLUSION}

1. Every organization goes through periods of creation and formation of activity, flourishing, gradual decline of productive activity and death. The future of the system is revealed and formed at the beginning of the stage of fading of productive activity. The struggle for selfpreservation is usually associated with increased systematization, i.e. administration. The duration of this process largely depends on the availability of external resources available to the system. If there is a timely reorientation in the activity of the organizational model of the system, its active components in the direction of increasing factorization due to the activity of beta-leaders, then a step - by-step-evolutionary, but still rapid transition to the next new round of its development is carried out.

In place of clearing-the creative destruction of an outdated organizational design, rather than the entire organizational model, a new one is generated. It is possible to convert one system into several more efficient systems. This is what can be considered a revolutionary, radical change in the development of society, although this is not possible without the evolutionary accumulation of quantitative changes in the organizational model, both during the period of rapid revolutionary changes and after, the transition to a new quality is impossible. If the system failed to manifest the forces that could generate the necessary changes in the basis of the organizational model and legalize new rules of behavior, then the collapse becomes inevitable. The preserved former components of the system have more ability to integrate into wellstructured systems, to be promoted to the top-leaders. Therefore, one or more other similar systems are reborn on the ruins of the old system. This change of power in the country is more correctly interpreted as a coup. There is often an initial movement to implement basic changes, but the ambiguity for most of the goals of this movement, the lack of the required rapid legislative consolidation of new rules of behavior is often replaced by a rollback to the usual behavior.

2. These changes cannot but concern labor relations and, accordingly, labor legislation, which should be based on timely adaptation to current trends. It becomes obvious that in the near future there will be an urgent need to move from rigid labor legislation and blurred discipline of economic entities to flexible labor legislation, which should be taken into account when developing modern approaches to accounting for the performance of high discipline of economic entities. In addition, with the increasing level of digitalization of production processes, the social component, the country's economy in particular and the globalization of economy in General, the introduction of new forms of employment, the adjustment of the concepts of "working time", "working day", "workplace" - is clearly necessary to fix at the legislative level.

The significance of the topic of digital technologies for the further development of Russia is no longer in doubt among both government representatives and the expert community. The main areas of digitalization of the domestic economy include "regulatory regulation of the digital environment", "information infrastructure", "personnel for the digital economy", "information security", "digital technologies", "digital public administration". In the development of this Federal program, programs for the digital development of the economy of the subjects of the Russian Federation are being developed. 
In each of the constituent entities of the Russian Federation innovative development is especially determined by the sectoral structure of the economy, level of technological development, the human potential in the field of science and innovation and other specific features.

\section{REFERENCES}

[1] D. Acemoglu, J.A. Robinson, Why are some countries rich and others poor, Publishing House AST, 2016.

[2] S.G. Karepova, I.S. Karabulatova, V.S. Novikov, S.V. Klemovitsky, D.I. Stratan, A.E. Perova, New Approaches to the Development of Methodology of Strategic Community Planning, Mediterranean Journal of Social Science 6,3,6 (2015) 357-364. DOI: 10.5901/mjss.2015.v6n3s6p357

[3] D. Beck, K. Cowan, Spiral dynamics: managing values, leadership and change, BestBusinessBooks, 2016.

[4] I.S. Karabulatova, M.S. Vykhrystyuk, N.G. Dolzhenko, E.I. Mychko, E.V. Potmenskaya, The Use of Stable Expressions in Modern Economic Discourse as an Emotional Increase in the Potential Impact on Purchasing Power, Space and culture 7(4) (2020) 283292. DOI: https://doi.org/10.20896/saci.v7i4.488

[5] H. Bloom, The Lucifer Principle: a Scientific Expedition into the Forces of History, 1995.

[6] Meme - what is it, Wikipedia, Available at: https://en.wikipedia.org/wiki/Meme.

[7] L. von Bertalanffy, General theory of systems-a Critical review, in: Research on General theory of systems: a Collection of translations, Progress, 1969.

[8] M.I. Setrov, Degree and height of the organization of systems, in: System research. Yearbook, Nauka, 1969.

[9] V.N. Volkova, A.A. Denisov, System Theory and system analysis: textbook for bachelors, Yurayt, 2013.

[10] F. Lala, Opening of the organization of the future, Mann, Ivanov and Ferber, 2016.

[11] A.N. Malyuta, Regularities of system development, Naukova Dumka, 1990.

[12] William Ross Ashby, Introduction to Cybernetics, Chapman \& Hall, 1956.
[13] R. Dawkins, The Selfish Gene (2 ed.), Oxford University Press, 1989.

[14] J. Tainter, The Collapse of Complex Societies, Cambridge University Press, 1990.

[15] V.V. Kozlov, Dynamics of development of socioeconomic systems, Investments in Russia 9(284) (2018) 10-15.

[16] B.R. Weingast, Why developing countries are so resistant to the rule of law, Institute of the European University in Florence, a series of lectures in the framework of the program 2 (2009), Available at: http://www.intelros.ru/pdf/Prognozis/ 02_2009/6.pdf.

[17] V.A. Engelhardt, About some attributes of life: hierarchy, integration, recognition, Questions of philosophy 7 (1976).

[18] A. Koestler, Beyond Atomisme and Holism, Beyond Reductionism, 1969.

[19] V.V. Kozlov, Modernization of the model of socio-economic system: evolution and revolution, foresight "Russia": the future of technology, Economics and human . Volume 2, in: Collection of reports of the V St. Petersburg international economic Congress (spec-2019), S.D. Bodrunov (Eds.), SaintPetersburg, INIR, 2019, p. 259.

[20] E. Rogers, Diffusion of Innovations, Simon and Schuster, 5th Edition, 2003.

[21] J.A.A. Schumpeter, Capitalism, Socialism and Democracy, Ekonomika, 1995.

[22] V.M. Efimov, Economic science under question: other methodology, history and research practices: a monograph, Moscow, Course: Infra-M, 2016.

[23] E. Ermakova, M. Jilkisheva, G. Fayzullina, I. Karabulatova, Kh. Shagbanova, The media end fiction: postmodernist discourse of contemporary terrorism in the context of apocalyptic rhetoric, Central Asia and Caucasus. Journal of Social and Political Studies 17,2 (2016) 61-69. 